\title{
Improving College And Career Readiness Through Challenge-Based Learning
}

Carl Shuptrine, Jackson Hole High School, USA

\begin{abstract}
High school students in an Advanced Video class addressed the challenge of increasing community awareness. Students followed a challenge-based learning model developing guiding questions and activities to determine solutions for implementation. Literature supported the use of project-based learning that fostered partnerships outside of the classroom to develop $21^{\text {st }}$ century skills. Students utilized multiple technologies to collaborate, plan, and produce advertising in a variety of mediums. During Phase 2, each team created videos documenting their entire process. Videos were presented to a group of random students and faculty members for critical review. Data were collected through pre and post surveys, observations, and student interviews. Data showed students found the process difficult but beneficial to developing $21^{\text {st }}$ century skills.
\end{abstract}

Keywords: Challenge-based Learning; Career Readiness; College Readiness; Career Technical Education; Community Partnerships; $21^{\text {st }}$ Century Skills

\section{INTRODUCTION}

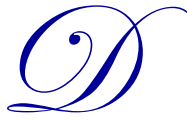

espite many secondary education students receiving complete coverage of core academic subjects, an increasing number were found to be under-prepared for the challenges they faced in post-secondary environments. Even academically high achieving students underachieved in college because they had not been taught the necessary skills to work through challenging situations (Balduf, 2009). This caused secondary schools to become increasingly focused on the concepts of career and college readiness.

While exploring student motivation and engagement, a study was conducted in a high school Advanced Video classroom that examined the relationship between project-based learning, career technical education (CTE), and the establishment of community and business partners to increase student motivation while simultaneously preparing secondary students for a variety of post-secondary environments. Research indicated strong correlations between each of these topics and student motivation and engagement. As a result, instruction was designed to merge all three into a singular learning experience.

Using a challenge-based learning model, a target audience of 10 students - nine male and one female spanning grades 10 through 12 were asked to address the challenge, "Increase Community Awareness." Data were collected and evaluated throughout the process in the form of of pre and post surveys, formal video interviews, student reflections, and rubric based assessment of guided activities. Students had access to a variety of computer and media production resources to utilize throughout the entire process.

The purpose of this study was to explore the effects of a challenge-based learning model implemented in a Career Technical Education classroom on student motivation, and the development of twenty-first century skills needed for career and college readiness.

Two hypotheses were drawn:

1. A Challenge-Based Learning methodology will increase student motivation and engagement.

2. A Challenge-Based Learning methodology will help students develop $21^{\text {st }}$ century skills. 


\section{LITERATURE REVIEW}

The following topics, which are partial results of previous research, were summarized and listed:

\section{Project Based Learning and Conditions of Flow}

In an examination of student motivation and engagement, J. Wilhelm and P. Wilhelm (2010) explored the conditions of flow experience, as characterized by Czikszentmihalyi (1990). They found that creating flow experience in a curriculum was highly beneficial to student engagement and learning. In turn, high levels of student motivation were shown to be a predictor of high school completion and continued success in college (David, Mihaly, Barbara, \& Steele, 2003). J. Wilhelm and P. Wilhelm identified inquiry approaches as meeting all of the required elements of flow. The inquiry process they described included devising essential questions, identifying culminating projects, and tailoring sequenced instruction for each student. The steps involved with inquiry approaches were nearly identical to the essential elements of project-based learning (PBL) outlined by Larmer and Mergendoller (2010); suggesting PBL as an effective strategy to generate student engagement and motivation.

Project-based learning needed to include a number of key elements to surpass simple busy work and actually engage students on a deep cognitive level (Larmer \& Mergendoller, 2010). These included the development of essential questions (Larmer \& Mergendoller, 2010; J. Wilhelm \& P. Wilhelm, 2010). These were defined as questions that did not have simple answers and encouraged students to formulate their own opinions as they acquired additional knowledge and fostered authentic lifelong learning (Brown, 2009; J. Wilhelm \& P. Wilhelm, 2010). Also included were a student's perception of personal control and their ability to see personal relevance within a specific curricular topic (Larmer \& Mergendoller, 2010). Finally, was the importance of creating a challenge that required a level of skill (J. Wilhelm \& P. Wilhelm, 2010). Studies indicated students reported the highest levels of engagement and attention when they participated in activities which contained challenges that required higher developed skills to complete (David, Mihaly, Barbara, and Steele, 2003). Used correctly, projectbased learning methods accounted for significant gains over traditional lecture and assignment delivery methods. (Özdener \& Özçoban, 2004; Chang \& Lee, 2010)

\section{Career Technical Education Supporting Post-secondary Transitions}

Many teachers did not utilize the project-based learning strategies due to perceptions that PBL took too much time to implement and required instructing additional technology skills (Chang \& Lee, 2010). One content area that regularly employed project-based learning methods was Career Technical Education (CTE) (Southern Regional Education Board, A. A., and Jobs for the Future, I. A., 2000). Team teaching models were proposed that paired experienced PBL technology instructors with core content teachers to enable students to experience first-hand the interrelation between content areas, thus improving the relevancy of what they were learning (Zirkle, 2004; Chang \& Lee, 2010). Additionally, Dare (2006) stated how combining CTE with more rigorous academic content was helping students as they transitioned to post-secondary education.

Expanding on these concepts, Gray (2004) argued that with over half of all students dropping out of high school or moving directly into the workforce after they graduated, combined CTE and academic curriculums were in fact relevant to a much larger student population than traditional or college preparatory programs. He stated that CTE classrooms exposed students to a variety of workplace experiences that helped them determine career plans, prepared them for a variety of post-secondary options, and were the only high school programs of study that prepared students for the abundance of highly technical jobs that awaited them after school. Mirroring these statements, Hyslop (2011) outlined the relationships between CTE, twenty-first century skills, and college or career readiness. She agreed that infusing all academic areas with the skills taught in CTE and twenty-first century learning courses would improve educational outcomes for all students.

\section{Community and Business Partnerships}

Hyslop (2011) argued for the importance of infusing all academic areas with the skills taught in Career Technical Education (CTE) and twenty-first century learning to support college and career readiness. However, to 
achieve this goal, she stressed the importance of CTE programs forming partnerships with local business communities to increase academic rigor and relevancy. Cole (2010) noted alternative benefits of community collaborations that were aligned with the concepts of creating personal relevance in education. Furthermore, studies showed that service learning projects placed students into a fluid environment filled with real-world complexities that required a wide range of skills to navigate and had the potential to foster relevant, meaningful learning by creating connections between students and local issues or challenges they found important (Cole, 2010; KenworthyU'Ren, 2003). Ultimately, schools that created support networks with families, businesses, and community organizations saw increases in student achievement (Anderson-Butcher el al., 2010).

Three areas were cited that contributed to the success or failure of a community-based learning program logistical flexibility, purposeful, deliberate planning that included establishing clear objectives and goals for both the students and the community partners, and targeted curricular activities to facilitate reflective thinking to help students make connections between their community-based experiences and broader contexts (Cole, 2010; Gerdes \& Ljung, 2009; Kenworthy-U'Ren, 2003).

\section{METHODOLGY}

\section{Phase 1}

For this study, two phases of Challenge-Based Learning (CBL) (Apple Incorporated, 2008) were implemented in a dual-credit Advanced Video high school classroom. A target audience of 10 students, grades 9-12, 9 male and 1 female completed a series of activities and were monitored throughout the process to help the facilitator evaluate whether the project was unfolding as planned. Throughout the process, the facilitator made recommendations for adjustments to the project based on a variety of data collection methods. Data were collected through a series of surveys, student reflection videos, formal interviews, and team updates. Additionally, all activities were evaluated on specific rubric-based requirements designed to evaluate the target audiences' application of the CBL process.

During Phase 1, students were asked to address the essential question, "How do we increase awareness of student involvement in the community?" The class started by generating guiding questions. At first all students attempted this individually. When it became clear that this process posed too much difficulty for many of the students, a class brainstorming session took place to develop a series of guiding questions, activities, and potential resources that could be used to develop a solution. Students continued to struggle with the process and conducted further review of the CBL website in order to watch videos to clarify questions about the big idea, essential questions, and what a solution could look like. The target audience also viewed some examples of what other students have done elsewhere.

Once students had developed a series of guiding questions, they began to collect data through the use of surveys. Some of these surveys were emailed to the student body of their school and others were administered by hand to members of their community at locations in their town. To get as many responses as they could from the student body, one team contacted local businesses and acquired gift certificates to award to randomly chosen survey respondents. The target audience also collected statistics from the front office of their school about student involvement in sports and clubs. Once their surveys were completed, they analyzed the results and developed targeted advertising in the form of paper flyers, a short video, a website, and a radio public service announcement to communicate the data they had collected to their chosen audiences.

During Phase 1, each team implemented a variety of technology tools. Team A utilized an online survey tool to generate a survey that they distributed to the student body via email. They also used page layout software to create flyers. Two flyers encouraged the student body to take their survey and one flyer displayed statistics based on the research they collected. Team A also created an original website to display the same information as the paper flyer. This team also utilized video editing software to create a short video about their process.

Team B also utilized an online survey tool. However, because they were collecting data from the public via paper surveys, they used it to manually input the data from these surveys and aggregate the results. This team chose 
to create a radio advertisement using digital audio editing software for broadcast on their high school low-power FM radio station.

As students worked toward a solution, they engaged in a variety of activities. They contacted local businesses to ask for donations. They met with other teachers and school administrators. They created videos for the school's display screens, public service announcements for the school radio station, and worked on a final presentation to show to the class. All activities engaged the target audience in high-level teamwork, communication, and problem-solving. Teams faced challenges and setbacks along the way, forcing them to modify their plans and adjust their solutions.

Both teams created multimedia presentations and presented them to the rest of the class. Team A created a short video in iMovie. Team B created a Keynote presentation. Both teams responded to questions from the other team and the instructor about their process.

\section{Phase 2}

In Phase 2, the target audience developed their own challenge to, "Increase understanding between communities in our school". Students immediately started working on guiding questions, activities, and identifying resources. A few students felt they understood the process and challenge well enough that they jumped directly to a solution.

Two of the three teams used a similar process to develop a solution. They conducted video interviews with students and teachers around the school to discover if any intolerance existed within the school. In reviewing their interviews, they identified subgroups that were mentioned more than others and decided to create informational videos highlighting these subgroups.

The third team jumped directly to a solution. Despite a number of attempts by the instructor to encourage them to conduct more research and explore other options, they failed to do so. They continued to pursue their first idea based on their own opinions and failed to ground their solution in research.

During Phase 2, the target audience primarily utilized a variety of video production tools throughout their entire process. All teams conducted formal interviews utilizing studio lighting and external microphones. Two teams made extensive use of a green screen studio to shoot a video for video compositing. Teams used both iMovie and Final Cut Pro to edit their videos. The teams that shot green screen footage utilized Apple's Motion to perform keying effects and create video composited scenes. All teams also utilized word processing software during their planning stages, and email to communicate with those outside of the class as well as with each other.

The instructor implemented two required activities in Phase 2. The first was a video "trailer" to present the teams' research and provide a preview of their implementation. The second element was a longer video documenting a team's entire process from beginning to end. Most of the activity in the classroom revolved around creating these two videos. These videos were presented to a guest panel of visiting teachers and students. Each team responded to questions from the guest panel and defended their process.

\section{RESULTS}

\section{Phase 1}

An assessment designed to measure intrinsic motivation was administered before and after Phase 1. Results were very similar with only slight variations throughout. Where there were variations, they appeared to indicate the following:

- $\quad$ Enjoyment of the Advanced Video class diminished slightly and some students found the CBL process to be less interesting than other classroom activities. Pre-survey data indicated that 8 out of 10 students strongly agreed that they enjoyed Advanced Video and found the class interesting while the remaining two 
moderately agreeing with these same statements. Post survey data showed an overall decrease in enjoyment as no students strongly agreed that they enjoyed Advanced Video anymore. Instead, six moderately agreed, three were neutral, and one slightly disagreed. Similarly, post-survey data indicated a slight drop in interest as six students only strongly agreed that Advanced Video was interesting, three moderately agreed, and one was neutral.

- $\quad$ Students believed they put forth greater effort during the CBL process. Pre-survey data showed that varying degrees of students believed they put a lot of effort into the Advanced Video class. One student strongly agreed with this statement, seven moderately agreed, one slightly agreed, and one strongly disagreed. Postsurvey data showed all ten students moderately or strongly agreed that they put a lot of effort into the advanced video class.

- $\quad$ Students perceived to have slightly less choice about their work than previous assignments. When asked about choice in the pre-survey, all ten students believed strongly, moderately, or slightly agreed they had some choice about the work they did in class. Post-survey data showed a decrease of one student who strongly agreed, a decrease of one student who slightly agreed, and two students who became neutral.

- $\quad$ The data indicated slightly lower intrinsic motivation in the class. The class average showed a decrease of half a percentage point of students who did work in the Advanced Video because they wanted to.

- $\quad$ Students were not as satisfied with their performance during the CBL process. Pre survey results indicated that all students were strongly, moderately, or slightly satisfied with their performance in the Advanced Video class. Post survey data showed a slight decrease with one fewer student who was strongly satisfied and one student who now was slightly dissatisfied.

- The students' perception of the importance of the Advanced Video class increased. Prior to Phase 1, all students moderately or strongly believed that Advanced Video was an important class. Once Phase 1 was complete, three additional students strongly believed that Advanced Video was an important class.

- $\quad$ Finally, multiple students cited dealing with surveys as a new skill and that the process brought attention to the importance of teamwork to the target audience. Most students ended the process indicating that the Advanced Video class would help them with project management and real-world skills.

\section{Phase 2}

During Phase 2 of the CBR, the target audience was split on their enjoyment level of Advanced Video. The split of enjoyment level correlated to the students who perceived their project to be successful versus those who did not. The three members of Team 1, who completed only a rough video of their interviews, reported the lowest levels of enjoyment. The members of Team 2, who had the most complete project, reported the highest levels of enjoyment with three members indicating strong enjoyment and one reporting moderate enjoyment. Team 3 , who was planning to implement a food day, had one member report strong enjoyment while the other two reported moderate enjoyment.

The overall interest level of the class was high, with $90 \%$ of the target audience reporting moderate and strong levels of interest. However, there was a slight decrease of interest level in the classroom activities during Phase 2 as $30 \%$ of the class decreased their interest level from strong to moderate. Based on many responses from the students, the decrease in interest is likely due to the "challenge" in challenge-based learning. This process forced students to address problems for which they did not have simple straightforward answers. Many times they were uncertain about how to move forward as, in the past, they always relied on the instructor to simply tell them what to do.

Oliver - Not having a centralized idea was really challenging...I sort of rely on being told what to do and when to do it

Almost all students indicated that this was the first time they had ever done anything like this in a school setting or otherwise.

Jimmie - No [I've never done anything like this] ...well maybe...well never like a huge...no, not really. 
The data appears to indicate that most of the students rose to the challenge by the end of Phase 2. Postsurvey results showed that $50 \%$ of the target audience strongly believed they tried very hard in class during Phase 2 , $30 \%$ were in moderate and slight agreement, and only $20 \%$ were neutral or believed the did not try very hard. This would appear to indicate high levels of intrinsic motivation in most of the students. What many of the students indicated they liked most about the project was the freedom and personal choice to determine the direction of their work. A few students also indicated that their work became personally relevant in some manner.

One student, however, perceived to have less control over their work. This is likely a result of having an attendance rate of around $60 \%$ due to winter sports travel. This particular student indicated that she felt out of the loop and would just be given assignments by her teammates to complete whenever she came back to class. This same student also indicated less interest in the project.

The data also showed that $60 \%$ of the target audience believed their video production skills were moderate or high after completing Phase 2. The four students from Team 2 believed their video production skills to be the strongest, with one member from each of the other teams also indicating high levels of production skill. Based on observation, these results correspond to each student's direct involvement with the videos their team produced.

Finally, despite not always liking it, the target audience almost universally stated that they found value in the process. When asked what they thought the work in Advanced Video could be useful for, they responded as follows:

Connor - My college career and work career

Jalaya - Making videos for fun, life skills, promotional videos, documentation and all kinds of videos

Wyatt - Team work and being able to solve broad problems

Ryder - Future careers, class and education, personal use follows:

Additionally, when asked what the work in Advanced Video could help them to do, they responded as

Tanner - Problem solve

Ryder - Work on future projects more efficiently, including both professional and personal

Josh - Get into a video production school

Wyatt - Solve real world problems; learn to work on a team

These responses indicated learning beyond a basic curriculum of video production and suggested that students found personal relevancy in their work while they developed many of the twenty-first century skills that were discussed in the research.

The reactions from others viewing the solutions were varied. Other teachers expressed the value they saw in the process but felt that most teams missed a few steps. Most feedback from both visiting students and teachers revolved around the target audience's lack of supporting evidence for their solutions.

Based on the findings above, research hypothesis \#1 was found to be inconclusive. Student engagement initially dropped due to level of the challenge being far above the students' skill level, but it rose by the end of Phase 2 as students became more comfortable with the learning process. Research hypothesis \#2 was confirmed as data indicated that the target audience primarily learned a variety of twenty-first century skills through the challengebased learning process.

\section{CONCLUSION}

As found by David, Mihaly, Barbara, and Steele (2003), conditions of flow were dependent on matching the level of curricular difficulty with students' levels of skill. Engagement was low when presented with a challenge they perceived to be far beyond their skill level; but once students had developed their skills sufficiently, flow experience was witnessed. Students would come to class and immediately begin working without any prompting from the instructor. Students also conducted work outside of regular class time to complete their projects. 
Results from Phases 1 and 2 also supported the research of Larmer and Mergendoller (2010) which indicated that a key component to engagement was the perception of student choice. The target audience indicated that they perceived less choice during Phase 1 than during previous course work. This may have contributed to the lack of engagement seen at the beginning of Phase 1. However, they indicated higher overall perception of choice by the end of Phase 2. This correlated to higher levels of engagement observed during Phase 2.

Responses from the target audience supported research by both Gray (2004) and Hyslop (2011) which stated that project-based learning methods implemented in Career Technical Education classrooms were highly beneficial to preparing students for a variety of post-secondary environments. Students learned and implemented twenty-first century skills throughout the CBR process to address challenging real-world scenarios. In addition, as predicted by Cole (2010), higher levels of intrinsic motivation were reported due to students pursuing learning that was personally relevant and made connections to local issues or challenges they found important.

Based on student responses during formal interviews conducted after the Phase implementations, the following conclusions were also made:

1. Students recognized the value of the process to help them prepare and work through challenging situations they might face in other classes or beyond their secondary education.

2. The challenge-based learning process teaches students a variety of twenty-first century skills to be successful in a variety of post-secondary environments. These skills include technology proficiency, problem-solving, systems analysis, project management, teamwork, and effective communication.

3. Responses from the target audience indicate that students are vastly underprepared for addressing challenging problems that do not have clear solutions. Since these are the types of challenges they are likely to face in any post-secondary environment, greater emphasis is needed in secondary education to teach students effective processes for working through real-world scenarios and implementing concrete and meaningful solutions.

4. Additionally, because of students' lack of exposure to these types of real-world projects, processes need to be presented in an organized manner that scaffolds learning so as to avoid overloading students with too much new information at the beginning of a challenge-based learning project.

5. When student teams created partnerships with businesses or communities outside of the classroom, they demonstrated greater motivation and indicated that they found their work to be more relevant and meaningful.

As educators search for teaching methods to increase student motivation in the classroom, challenge-based learning has emerged as a pedagogy that serves this purpose by creating conditions of flow during content acquisition. Unfortunately, most academic classrooms continue to deliver content in traditional methods resulting in a lack of engagement among students. The one area of study that does employ project-based learning is Career Technical Education. As a result, educators should consider enacting team teaching methods that combine CTE with core academic programs to allow students to experience higher levels of engagement in their learning and increased retention of curricular information. By implementing these methods, research showed that students attained higher levels of achievement in both content areas and developed intrinsic motivations to advance their learning. These programs enable students to develop the skills needed to navigate the challenging situations encountered in postsecondary environments while simultaneously connecting classroom learning to personally relevant, real-world applications. By integrating core subject matter within the technical training and community-oriented, project-based learning methods of Career Technical Education, students acquire the necessary skills to be successful in the twentyfirst century.

\section{ACKNOWLEDGEMENTS}

Roxanne De Leon, Capstone Project Advisor, Education Media Design and Technology Master of Science, Full Sail University 


\section{AUTHOR INFORMATION}

Carl Shuptrine is a professional educator with seven years of teaching experience, preceded by five years of work in the television production industry. Currently a teacher of Media Arts at Jackson Hole High School, he earned his undergraduate degree in Fine Arts at Rhode Island School of Design. He then pursued a career in the television industry working as a news anchor/reporter, a motion graphics designer in Ho Chi Minh City, Vietnam, and an editor for an action sports production studio. He completed a Master's of Science at Full Sail University in the Education Media Design and Technology program. He is happily married and has two beautiful, spirited daughters. E-mail: cshuptrine@tcsd.org

\section{REFERENCES}

1. Anderson-Butcher, D., Lawson, H. A., Iachini, A., Flaspohler, P., Bean, J., \& Wade-Mdivanian, R. (2010). Emergent evidence in support of a community collaboration model for school improvement. Children \& Schools, 32(3), 160-171. Retrieved from Academic Search Complete.

2. Apple Incorporated. (2008). Challenge based learning: Take action and make a difference. Retrieved from http://www.apple.com/education/challenge-based-learning/

3. Balduf, M. (2009). Underachievement among college students. Journal of Advanced Academics, 20(2), 274-294. Retrieved from ERIC.

4. Brown, K. (2009). Questions for the 21st-century learner. Knowledge Quest, 38(1), 24-29. Retrieved from http://www.ala.org/ala/mgrps/divs/aasl/aaslpubsandjournals/knowledgequest/knowledgequest.cfm

5. Chang, L., \& Lee, G. C. (2010). A team-teaching model for practicing project-based learning in high school: Collaboration between computer and subject teachers. Computers \& Education, 55(3), 961-969. Retrieved from http://dx.doi.org/10.1016/j.compedu.2010.04.007

6. Cole, A. (2010). School-community partnerships and community-based education: A case study of a novice program. Perspectives on Urban Education, 7(1), 15-26. Retrieved from Education Research Complete.

7. Dare, D. E. (2006). The role of career and technical education in facilitating student transitions to postsecondary education. New Directions for Community Colleges, (135), 73-80. doi:10.1002/cc.249.

8. David J., S., Mihaly, C., Barbara, S., \& Elisa Steele, S. (2003). Student engagement in high school classrooms from the perspective of flow theory. School Psychology Quarterly, 18(2), 158-176. Retrieved from Academic Search Complete.

9. Gerdes, D., \& Ljung, E. (2009, September). The students have the answers. Educational Leadership, 67(1), 71-75. Retrieved from Academic Search Complete.

10. Gray, K. (2004). Is high school career and technical education obsolete? Phi Delta Kappan, 86(2), 128-134. Retrieved from Education Research Complete.

11. Hyslop, A. (2011, March). CTE and 21st century skills in college and career readiness. Techniques: Connecting Education \& Careers, 86(3), 10-11. Retrieved from Academic Search Complete.

12. Kenworthy-U'Ren, A. (2003). Service-learning and negotiation: Engaging students in real-world projects that make a difference. Negotiation Journal, 19(1), 51. Retrieved from Business Source Complete.

13. Larmer, J., \& Mergendoller, J. R. (2010). 7 essentials for project-based learning. Educational Leadership, 68(1), 34-37. Retrieved from Academic Search Complete.

14. Özdener, N., \& Özçoban, T. (2004). A project based learning model's effectiveness on computer courses and multiple intelligence theory. Educational Sciences: Theory \& Practice, 4(1), 176-180. Retrieved from Academic Search Complete.

15. Southern Regional Education Board, A. A., \& Jobs for the Future, I. A. (2000). Using real world projects to help students meet high standards in education and the workplace. Site Development Guide \#11. High

Schools That Work. Retrieved from http://www.sreb.org/programs/hstw/publications/siteguides/UsingRealWorldProjects.pdf

16. Wilhelm, J. D., \& Wilhelm, P. J. (2010, May). Inquiring minds learn to read, write, and think: Reaching all learners through inquiry. Middle School Journal, 41(5), 39-46. Retrieved from http://www.nmsa.org.

17. Zirkle, C. (2004). Integrating occupational and academic skills across the curriculum. Techniques: Connecting Education and Careers, 79(6), 24-26. Retrieved from http://acte.hodgsonconsult.com/content.aspx?id=5790 